\title{
PENGEMBANGAN MULTIMEDIA INTERAKTIF BERBASIS NILAI KARAKTER UPY “KARAKTERKU” UNTUK MENINGKATKAN KARAKTER MAHASISWA UPY
}

\author{
Sukadari $^{(1)}$, Mahilda Dea Komalasari ${ }^{(2)}$ \\ Program Studi PIPS Pascasarjana \\ Program Pasca Sarjana \\ Universitas PGRI Yogyakarta \\ E-mail: sukadariupy@gmail.com
}

\begin{abstract}
Abstrak
Penelitian pengembangan multimedia interaktif berbasis nilai karakter UPY 'Karakterku' ini bertujuan untuk meningkatkan karakter mahasiswa UPY. Metode penelitian yang digunakan adalah penelitian pengembangan. Pengumpulan data pada penelitian ini antara lain adalah observasi, angket, wawancara dan tes. Metode analisa data yang dilakukan pada penelitian ini adalah analisis kuantitatif menggunakan paired sample t-test. Hasil penelitian ini adalah multimedia interaktif berbasis nilai karakter UPY 'Karakterku' yang dikembangkan melalui 6 langkah penelitian dan pengembangan yaitu penelitian dan pengumpulan, perencanaan, pengembangan draf produk, ujicoba lapangan awal, merevisi hasil uji coba dan uji coba lapangan.Berdasarkan hasil penelitian diketahui bahwa nilai significansi karakter mahasiswa dengan menggunakan multimedia interaktif 'Karakterku' adalah 0,000 maka terdapat perbedaan prestasi dengan sebelum dan setelah menggunakan multimedia interaktif.
\end{abstract}

Kata kunci: multimedia interaktif, karakterku, karakter mahasiswa

\begin{abstract}
Research and development of interactive multimedia based on UPY character values 'Karakterku'is aims to improve the character of UPY students. The research method is used research and development. Data collection in this study include observation, questionnaires, interviews and tests. Method of data analysis conducted in this research is quantitative analysis using paired sample t-test. The result of this research is interactive multimedia based on the UPYcharacter values 'Karakterku' which developed through 6 steps of research and development that are research and collecting, planning, product draft development, initial field trial, revise test result and field trial. Based on the survey results revealed that the significansiofcharacterby using interactive multimedia 'Karakterku' is 0,000 then there are differences in achievement with before and after using interactive multimedia.
\end{abstract}

Keywords: interactive multimedia, karakterku, character of the student

\section{Info Artikel}

Diterima Oktober 2017, disetujui November 2017, diterbitkan Desember 2017 


\section{PENDAHULUAN}

Mahasiswa merupakan generasi penerus bangsa yang perlu mendapatkan pendidikan serta pengembangan diri agar potensinya dapat berkembang optimal dan memiliki kepribadian tangguh, serta memiliki berbagai macam kemampuan maupun keterampilan yang bermanfaat.Mahasiswa berada pada taraf perkembangan remaja akhir menuju dewasa. Masa ini merupakan masa yang penting bagi individu dalam pemantapan mental maupun spiritual, sehingga perlu dilakukan pemantapan karakter yang baik pada masa tersebut supaya menjadi bekal untuk kehidupannya di masa depan.

Proses pemantapan karakter ini juga dipengaruhi oleh media teknologi informasi dan komunikasi. Kemajuan teknologi yang semakin pesat semakin membuka peluang transfer informasi yang tak terbatas. Transfer informasi yang tak terbatas dapat berdampak positif dan negatif. Dampak negatifnya adalah mudahnya mengakses informasi-informasi yang memuat karakter negatif.Di era globalisasi, teknologi, telekomunikasi dan perdagangan telah membuka sekat-sekat antar negara.Arus globalisasi ini mengakibatkan masuknya berbagai budaya asing ke Indonesia.Hal ini merupakan ancaman terbesar yang dihadapi oleh setiap negara. Ancaman tersebut dapat menimbulkan krisis sosial, intelektual, moral, dan yang terparah adalah krisis karakter yang menjurus kepada krisis identitas bangsa.Masalah fundamental lainnya dari ancaman globalisasi adalah keterbukaan informasi yang memudahkan berbagai macam ideologi asing yang masuk ke Indonesia dan mengancam runtuhnya karakter bangsa Indonesia dan memicu maraknya kasus-kasus dekadensi karakter.

Kasus dekadensi karakter banyak terjadi di masyarakat.Dengan demikian, perguruan tinggi memiliki peran yang cukup besar dalam rangka mengembangkan karakter mahasiswa untuk melanjutkan kehidupan dan menyiapkannya untuk terjun ke masyarakat.Salah satu strategi untuk mengembangkan nilai karakter pada mahasiswa adalah dengan memasukkan nilai karakter ke dalam visi misi perguruan tinggi yang kemudian dituangkan dalam suatu slogan atau semboyan, agar mahasiswa menyadari dan memahami nilai karakter yang perlu dikembangkan. Hal tersebut dikarenakan nilai karakter yang tertuang dalam slogan akan sering dibaca sehiingga cepat diserap otak.

Eksistensi suatu bangsa ditentukan oleh karakter yang dimiliki bangsa tersebut.Terkait dengan hal itu, Universitas PGRI Yogyakarta (UPY) berupaya melahirkan akademikus yang cerdas maupun berkarakter, selanjutnya nilai karakter tersebut tertuang dalam visi UPY yaitu "Pada tahun 2030, UPY menjadi Perguruan Tinggi unggul, menghasilkan lulusan yang bertaqwa, kompetitif, 
professional, memiliki komitmen nasional dan berwawasan global".Untuk merealisasikan visi tersebut, dibuatlah slogan Karakter UPY 'Karakterku', yang berisi sembilan nilai karakter utama yang dimiliki oleh seluruh civitas akademik UPY. Sembilan nilai karakter tersebut yaitu: 1) keimanan dan ketaqwaan; 2) amanah atau kejujuran; 3) rasa nasionalisme dan patriotisme; 4) akademikus atau cerdas dan kompetitif; 5) kemanusiaan atau humanism; 6) terbuka dan adil; 7) empati dan tangguh; 8) rukun dan musyawarah; 9) kebhinekaan dalam persatuan; dan 10) Universitas PGRI Yogyakarta.

Nilai "Karakterku" merupakan kristalisasi dari nilai-nilai Pancasila dan berakar dari budaya dan pandangan hidup bangsa Indonesia, harus dijunjung tinggi oleh segenap civitas akademika UPY karena "Karakterku" merupakan cerminan jiwa dan kepribadian bangsa Indonesia. Nilai "Karakterku" apabila diimplementasikan dengan baik dapat berperan untuk mengantisipasi terjadinya dekadensi karakter mahasiswa, karena mengamalkan "Karakterku" berarti melaksanakan Pancasila dalam kehidupan seharihari, dan mengamalkan Pancasila sebagai petunjuk hidup sehari-hari dapat mencapai kesejahteraan dan kebahagiaan lahir dan batin. Namun "Karakterku" yang seharusnya menjadi falsafah bangsa dan fondasi kehidupan masyarakat kenyataannya lebih sering dipajang sebagai semboyan belaka.Hal itu terlihat dari banyaknya mahasiswa yang tidak memahami dan mengamalkan nilai "Karakterku" dalam kehidupan seharihari serta belum optimalnya media untuk menyosialisasikan nilai “Karakterku" pada warga UPY. Untuk mengatasi kurangnya pemahaman mahasiswa terhadap nilai "Karakterku", maka nilai-nilai karakter dalam "Karakterku" perlu diintegrasikan ke dalam pembelajaran.

Dalam hal ini perlu dilakukan upaya untuk mengoptimalkan pengembangan karakter tersebut, salah satunya dapat dilakukan dengan bantuan teknologi multimedia.Oleh karena itu, penting dilakukan penelitian pengembangan multimedia interaktif berbasis nilai karakter UPY "Karakterku" untuk meningkatkan karakter mahasiswa UPY.

Nilai karakter UPY yang terangkum dalam sebuah semboyan 'Karakterku' terdiri dari nilai karakter berikut:

a. Keimanan dan ketaqwaan

Keimanan adalah suatu proses kejiwaan yang tercakup di dalamnya semua fungsi jiwa, perasaan dan pikiran sama-sama meyakinkannya (Zakiah Daradjat, 1990: 14-16). Di bagian lain, Shodiq (2014: 133-135) menjelaskan bahwa keimanan adalah proses kejiwaan yang melibatkan fungsi kognisi dan afeksi secara bersama, sedangkan ketaqwaan berasal dari kata taqwa. 
Kata takwa berasal dari bahasa Arab yaitu Ittaqa-Yattaqi-Ittiqaan, yang artinya takut (Abboed S. Abdullah, 1988: 50). Lebih luas pengertian takwaadalah menjaga diri dari siksaan Tuhan dengan cara mengikuti segala perintahNya dan menjauhi larangan-Nya (Pius A. Partanto \& M. Dahlan Al Barry, 1994: 735), sedangkan menurut Syeikh Abdul Qadir AlJilani (2002: 51), orang yang bertakwa adalah orang yang tidak lepas dari perbuatan mensucikan diri; orang yang selalu berusaha membenamkan dirinya dalam perbuatan yang diridhai Tuhan serta menjauhkan diri dari perbuatan yang dimurkai Tuhan.

b. Amanah atau kejujuran

Amanah merupakan sikap menghilangkan khianat. Orang yang amanah berarti orang yang telah dipercaya sehingga orang lain merasa aman dan tenteram untuk memberikan amanah kepadanya (Agung Trana Jaya, 2011: 50). Mubarok (2009) mendefinisikan amanah sebagai sikap mental yang di dalamnya terkandung unsur kepatuhan kepada hukum (baik hukum agama maupun hukum positif), tanggung jawab akan tugas, kesetiaan pada komitmen, keteguhan memegang janji, kesucian dalam tekad dan kejujuran terhadap diri sendiri.

c. Rasa nasionalisme dan patriotism

Nasionalisme berasal dari kata nation yang berarti
bangsa.Nasionalisme merupakan paham yang berpandangan bahwa kesetiaan yang tertinggi harus diserahkan pada negara kebangsaan.Taniredja (2013: 185), sedangkan patriotisme lebih menekankan pada cinta dan loyalitas pada Negara (Blank \& Schmidt, 2003).

d. Akademikus atau cerdas dan kompetitif

Menurut KBBI, akademikus berarti orang yang berpendidikan perguruan tinggi, sedangkan kompetitif adalah suatu hal yang berhubungan dengan sebuah persaingan/kompetisi.

e. Kemanusiaan atau humanisme

Nilai kemanusiaan terkandung bahwa suatu instansi harus menjunjung tinggi harkat dan martabat manusia sebagai makhluk yang beradab.

f. Terbuka dan adil

Istilah terbuka dalam penelitian ini bermaksud berpikiran terbuka.Berpikir terbuka yaitu suatu aktivitas otak yang terbuka menerima berbagai ide, pandangan, argumen, data, teori, maupun kesimpulan, sedangkan keadilan mengandung suatu makna bahwa hakikat manusia sebagai makhluk yang berbudaya dan beradab harus berkodrat adil.Bahwa hakikat manusia harus adil dalam hubungan diri sendiri, adil terhadap sesama manusia, adil terhadap bangsa dan negara, adil 
terhadap lingkungannya serta adil terhadap Tuhan Yang Maha Esa.

g. Empati dan Tangguh

Empati merupakan kemampuan individu untuk memahami dan ikut merasakan perasaan orang lain dalam bentuk ungkapan verbal maupun perilaku, serta dapat mengkomunikasikan pemahaman tersebut kepada orang lain, sedangkan orang yang tangguh yaitu mampu mengatasi rintangan, dan memimpin orang lain dalam melewati situasi berbahaya, serta tetap tegar dan kuat dalam kondisi apapun.

h. Rukun dan musyawarah

Hidup rukun artinya saling menghormati dan menyayangi antara sesama manusia, sedangkan musyawarah berasal dari kata Syawara yaitu berasal dari Bahasa Arab yang berarti berunding, urun rembuk atau mengatakan dan mengajukan sesuatu.

i. Kebhinekaan dalam Persatuan

Kebhinekaan dalam persatuan bermakna bahwa perbedaan diciptakan untuksaling menguntungkan persatuan dalam kehidupan bersama guna mewujudkan tujuan bersama, dan bukan untuk menimbulkan permusuhan.

\section{METODE PENELITIAN}

\section{Pendekatan dan Desain Penelitian}

Desain penelitian yang digunakan dalam penelitian pengembangan multimedia interaktif berbasis nilai karakter UPY "Karakterku" untuk meningkatkan karakter mahasiswa UPY ini menggunakan siklus tahapan pengembangan Research \& Development (R\&D) dariBorg \& Gall. Multimedia interaktif ini akan diuji secara teoritik maupun secara empirik di lapangan setelah ditemukan multimedia interaktif secara tentatif melalui penelitian pendahuluan.

\section{Populasi dan Sampel Penelitian}

Populasi penelitian ini adalah mahasiswa kelas A6-15 prodi PGSD Universitas PGRI Yogyakarta.

\section{Instrumen Pengumpulan Data}

Instrumen yang digunakan dalam pengembangan media visualisasi ini adalah observasi, angket atau kuesioner, dan tes.

\section{Teknik Analisis Data}

Teknik analisis data yang digunakan dalam penelitian dan pengembangan ini adalah teknik analisis data kuantitatif.Data kuantitatif diperoleh dari angket penilaian validator dan hasil angket karakter mahasiswa.

\section{HASIL PENELITIAN DAN PEMBAHASAN}

Pengembangan multimedia interaktif berbasis nilai karakter UPY "Karakterku" menggunakan model pengembangan Borg \& Gall, yaitu: 
Penelitian dan Pengumpulan Data (research and information collecting)

Pada tahap penelitian dan pengumpulan data (research and information collecting), dilakukan penelitian pendahuluan berupa wawancara dan survey mengenai pemahaman nilai karakter UPY 'Karakterku' mahasiswa PGSD UPY Kelas A6-15.

Hasil wawancara dengan mahasiswa PGSD UPY Kelas A6-15 diketahui bahwa banyak mahasiswa yang belum memahami makna dari nilai karakter UPY 'Karakterku' karena belum ada kajian mendalam untuk mahasiswa tentang pengertian dari 'Karakterku', meskipun slogan 'Karakterku' sudah terpampang lama di kampus, namun mahasiswa banyak yang tidak hafal tentang 9 nilai 'Karakterku'. Berdasarkan wawancara dengan mahasiswa tersebut, pengembangan multimedia interaktif berbasis nilai karakter UPY 'Karakterku' sangat penting dilakukan untuk menambah pemahaman mahasiswa terhadap nilai karakter UPY 'Karakterku'.

Hasil survey pemahaman nilai karakter UPY 'Karakterku' pada mahasiswa PGSD UPY kelas A6-15 ditunjukkan pada grafik berikut..

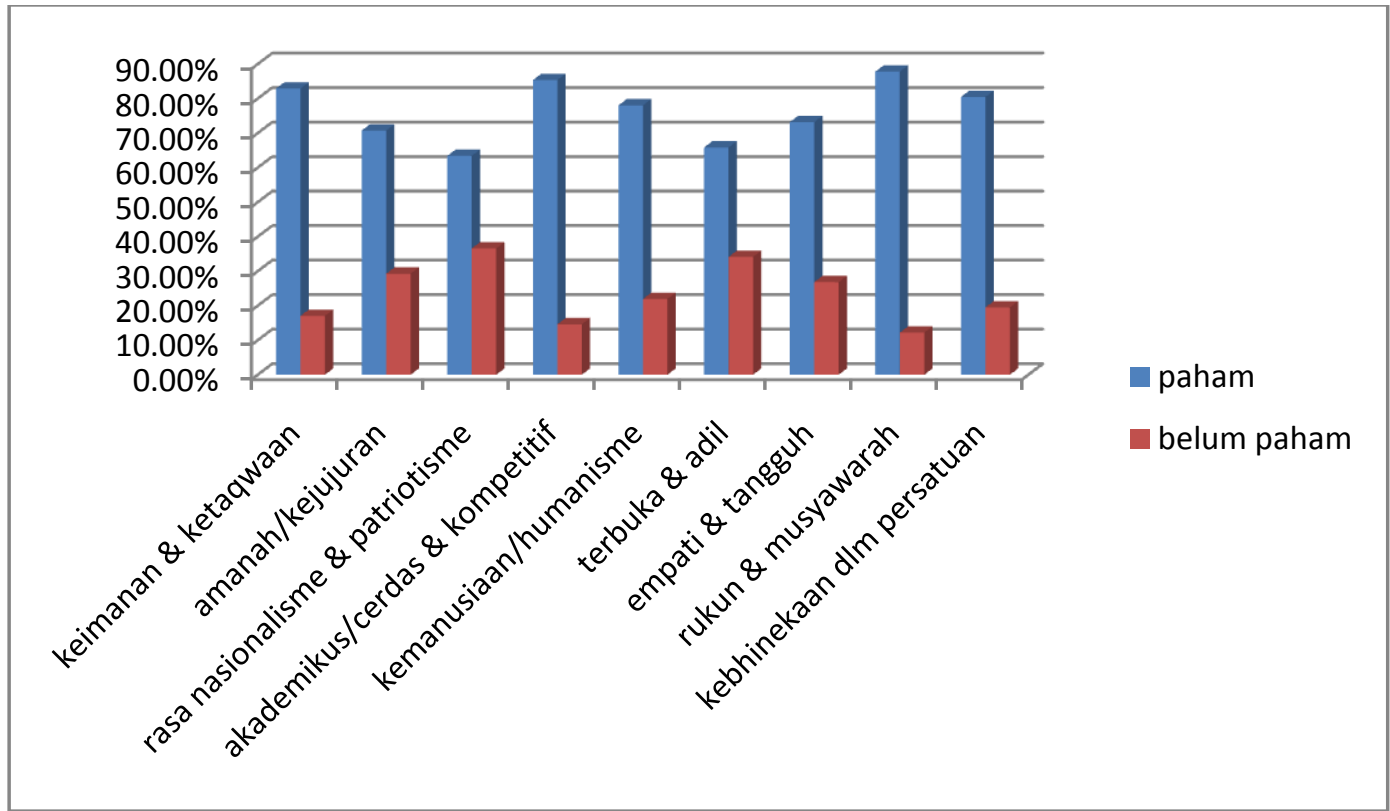

Gambar 1. Grafik Presentase Pemahaman Mahasiswa Kelas A6-15 terhadap Nilai 'Karakterku' Dilihat dari Tiap Nilai Karakter

Grafik di atas menjelaskan bahwa dari total 41 mahasiswa kelas A6-15, terdapat 34 mahasiswa
$(82,93 \%)$ yang memahami karakter 'keimanan dan ketaqwaan', 29 mahasiswa $(70,73 \%)$ yang memahami 
karakter 'amanah atau kejujuran', 26 mahasiswa $(63,41 \%)$ memahami karakter 'rasa nasionalisme \& patriotisme', 35 mahasiswa $(85,37 \%)$ memahami

karakter 'akademikus/cerdas \& kompetitif', 32 mahasiswa $(78,05 \%)$ memahami karakter 'kemanusiaan/humanisme', 27 mahasiswa $(65,85 \%)$ memahami karakter 'terbuka \& adil', 30 mahasiswa $(73,17 \%) \quad$ memahami karakter 'empati \& tangguh', 36 mahasiswa $(87,80 \%)$ memahami karakter 'rukun \& musyawarah', dan 33 mahasiswa $(80,49 \%)$ memahami karakter 'kebhinekaan dalam persatuan'.

Berdasarkan need assessment, ditemukan bahwa mahasiswa UPY belum sepenuhnya memahami pengertian dari 9 nilai karakter UPY 'Karakterku'. Hasil survei lapangan juga menunjukkan bahwa belum ada buku saku tentang materi 'Karakterku'.Berdasarkan kebutuhan tersebut, maka peneliti mengembangkan multimedia interaktif berbasis nilai karakter UPY 'Karakterku' untuk meningkatkan karakter mahasiswa UPY.

\section{Perencanaan (planning)}

Pada tahap perencanaan (planning), peneliti kemudian menyusun rencana peneltian yaitu pengembangan multimedia interaktif berbasis nilai karakter UPY 'Karakterku'.
Pengembangan Draf Produk

(Develop Preliminary Form Of Product).

Pada tahap ini dilakukan pengembangan bahan pembelajaran dan instrumen evaluasi. Bahan pembelajaran (terlampir) kemudian diaplikasikan dalam bentuk multimedia intraktif. Evaluasi dilihat dari segi pemahaman dan sikap mahasiswa terhadap nilai-nilai 'Karakterku'. Sikap mahasiswa terhadap nilai 'Karakterku' diukur dengan menggunakan angket.

Validasi desain dilakukan dengan meminta ahli materi dan media untuk menilai produk media yang telah dibuat. Penilaian dilakukan untuk mengetahui kekurangan, kekuatan, dan kualitas dari produk media. Dalam penelitian ini melibatkan 2 orang ahli materi dan 2 orang ahli media sebagai validator.

Validasi materi dilakukan untuk menilai produk media dari aspek isi dan pembelajaran. Ahli materi yang melakukan validasi kualitas dan produk media ini merupakan dosen PGSD UPY yang mengampu mata kuliah Pendidikan Kewarganegaraan. Berdasarkan penilaian tersebut maka dapat disimpulkan bahwa ahli materi menyatakan bahwa kualitas multimedia interaktif berbasis nilai karakter UPY 'Karakterku' dari segi materi berada dalam kriteria sangat baik.

Validasi media dilakukan untuk menilai produk media dari desain tampilan, komunikasi visual, dan 
perangkat lunak. Ahli media yang melakukan validasi media dalam penelitian ini adalah dosen PGSD UPY yang mengampu mata kuliah Pengembangan Media Pembelajaran Interaktif. Adapun penilaian ahli media adalah sebagai berikut: Berdasarkan penilaian tersebut maka dapat disimpulkan bahwa ahli media menyatakan bahwa kualitas multimedia interaktif berbasis nilai karakter UPY 'Karakterku' dari segi kualitas media berada dalam kriteria sangat baik.

\section{Uji Coba Lapangan Awal}

Uji coba lapangan awal ini dilakukan oleh beberapa mahasiswa PGSD UPY. Uji coba ini bertujuan untuk mengetahui kelayakan produk sebelum diujicobakan pada uji coba lapangan. Uji coba lapangan awal ini dilakukan oleh 8 mahasiswa PGSD kelas A7-15. Data hasil ujicoba tersebut diukur dalam angket respon mahasiswa. Berdasarkan data penilaian mahasiswa melalui angket respon mahasiswa diketahui bahwa kualitas multimedia interaktif berbasis nilai karakter UPY 'Karakterku' tergolong dalam kriteria baik.

\section{Merevisi Hasil Uji Coba (Main Product Revision).}

Data hasil uji coba awal menunjukkan bahwa kualitas multimedia interaktif berdasarkan respon mahasiswa termasuk dalam katagori baik. Namun walaupun begitu, guru memberikan beberapa saran perbaikan. Berdasarkan saran tersebut, peneliti melakukan revisi produk multimedia interaktif berbasis nilai karakter UPY 'Karakterku' yaitu dengan mensetting waktu pembicaraan dan volume pembicaraan dalam film animasi tersebut.

\section{Uji Coba Lapangan (Main Field)}

Uji coba ini bertujuan untuk mengetahui hasil pembelajaran setelah menggunakan multimedia interaktif berbasis nilai karakter UPY 'Karakterku'. Dalam hal ini hasil ujicoba dibandiingkan antara pretes dengan postes mengunakan multimedia interaktif berbasis nilai karakter UPY 'Karakterku'. Uji coba dilakukan pada 1 kelas yaitu kelas A615 dengan 41 orang subjek.

Berdasarkan ujicoba tersebut diketahui bahwa terdapat perbedaan karakter pada kelompok pretes dan postes. Karakter mahasiswa UPY pada level 'valuing' diukur dengan menggunakan angket. Pengaruh multimedia interaktif berbasis nilai karakter UPY 'Karakterku' terhadap karakter mahasiswa UPY dilihat dari perbedaan karakter sebelum dan sesudah menggunakan multimedia interaktif berbasis nilai karakter UPY 'Karakterku'. Untuk mengetahui perbedaan tersebut dilakukan uji hipotesis. Sebelum dilakukan uji hipotesis dilakukan terlebih dahulu uji prasyarat yaitu uji homogenitas dan uji normalitas sebagai berikut. 
Uji normalitas dilakukan dengan uji Kolmogorov-Smirnov. Hipotesis dari uji normalitas adalah:

Ho : Data memiliki distribusi tidak normal

$\mathrm{Ha}$ : Data memiliki distribusi normal

Berikut ini adalah hasil uji normalitas yang perhitungannya menggunakan bantuan program SPSS.Berdasarkan hasil analisis data diketahui bahwa nilai signifikansi pembelajaran sebelum menggunakan multimedia interaktif adalah 0,257 dan nilai signifikansi setelah menggunakan multimedia interaktif adalah 0,042. Nilai significansi postes lebih besar dari 0,05. Dengan demikian dapat disimpulkan bahwa Ho diterima dan data dari kedua variabel tersebut berdistribusi tidak normal.

Berdasarkan uji prasyarat diketahui bahwa data pretes dan postes tidak normal. Sehingga uji hipotesis dapat dilakukan secara non parametrik dengan menggunakan 2 related samples. Hipotesis yang diuji adalah sebagai berikut.

Ho: Tidak terdapat perbedaan karakter antara kelompok yang tidak menggunakan multimedia interaktif berbasis nilai karakter UPY 'Karakterku'.

Ha: Terdapat perbedaan karakter antara kelompok yang tidak menggunakan multimedia interaktif berbasis nilai karakter UPY 'Karakterku'.

Berikut adalah hasil uji t-test yang telah dilakukan.
Test Statistics ${ }^{\mathrm{a}}$

\begin{tabular}{|lr|l|}
\hline & & nilai - tes \\
\hline $\mathrm{Z}$ & & $-7.868^{\mathrm{b}}$ \\
$\begin{array}{l}\text { Asymp. } \\
\text { tailed) }\end{array}$ & Sig. $\quad(2-$ & .000 \\
\hline
\end{tabular}

a. Wilcoxon Signed Ranks Test

b. Based on negative ranks.

Berdasarkan tabel di atas diketahui bahwa nilai significansi 0,000 maka Ho ditolak jadi dapat disimpulkan bahwa terdapat perbedaan karakter dengan menggunakan multimedia interaktif berbasis nilai karakter UPY 'Karakterku'

\section{PEMBAHASAN}

Berdasarkan hasil penelitian di atas diketahui bahwa nilai nilai signifikansikarakter mahasiswa dengan menggunakan multimedia interaktif 'Karakterku' adalah 0,000maka Ho ditolak dan Ha diterima, sehingga dapat disimpulkan bahwa terdapat perbedaan karakter mahasiswa menggunakan multimedia interaktif.

Hal tersebut sesuai dengan penelitian Aditya Rizky Prapasa (2015) dengan judul "Pengembangan Multimedia Pembelajaran Interaktif Matematika Berbasis Pendidikan Karakter Menggunakan Macromedia Flash Professional 8 pada Pokok Bahasan Himpunan", hasil analisis datanya membuktikan bahwa kualitas multimedia pembelajaran interaktif matematika menggunakan macromedia flash profesional 8 pada 
pokok bahasan himpunan memiliki kualitas Sangat Baik (SB) dengan nilai $87,87 \%$ dan respon siswa terhadap Media Pembelajaran hasil pengembangan adalah sangat baik dengan nilai $89,84 \%$. Berdasarkan penilaian dari validator ahli madia dan ahli materi serta mendapatkan respon siswa SB dengan nilai lebih dari 85\%, maka Multimedia pembelajaran hasil pengembangan dinyatakan layak digunakan untuk penelitian.

Peneliti berikutnya adalah Mariana, Zulkifli, \& Ermina Sari yang meneliti dengan judul "Peningkatan Keterampilan Berpikir Kritis sebagai Pembentuk Karakter Calon Guru Biologi pada 3 Varian Multimedia yang Berbeda". Hasil penelitian menunjukkan bahwa ketiga varian multimedia berbeda secara signifikan dalam meningkatkan keterampilan berpikir kritis calon guru biologi.Perbedaannya dengan penelitian ini yaitu pada penelitian ini lebih menekankan pengembangan multimedia interaktif yang berbasis nilai karakter UPY "Karakterku”.

Selanjutnya, penelitian Asni Widiastuti \& Muhammad Nur Wangid (2015) dengan judul "Pengembangan Multimedia Lectora pada Pembelajaran TematikIntegratif Berbasis Character Building bagi Siswa Kelas IV SD”. Hasil penelitian menunjukkan bahwa multimedia hasil pengembangan menurut ahli materi maupun ahli media terkategori "sangat baik" sehingga layak digunakan, serta terdapat efektivitas penggunaan multimedia yang signifikan pada pembelajaran sebelum dan sesudah menggunakan multimedia interaktif Lectora dengan hasil signifikansi $0,0001<0,05$.

Jadi berdasarkan ketiga penelitian di atas dapat disimpulkan bahwa multimedia interaktif dapat meningkatkan karakter mahasiswa UPY.

\section{SIMPULAN IMPLIKASI DAN SARAN \\ Simpulan}

Berdasarkan hasil penelitian dan pembahasan, maka dapat disimpulkan sebagai berikut.

1. Pengembangan multimedia interaktif berbasis nilai karakter UPY 'Karakterku' dikemmbangkan dengan 6 langkah penelitian dan pengembangan yaitu penelitian dan pengumpulan, perencanaan, pengembangan draf produk, ujicoba lapangan awal, merevisi hasil uji coba dan uji coba lapangan.

2. Berdasarkan hasil penelitian di atas diketahui bahwa nilai significansi karakter mahasiswa dengan menggunakan multimedia interaktif 'Karakterku' adalah 0,000 maka terdapat perbedaan prestasi dengan sebelum dan setelah menggunakan multimedia interaktif. 


\section{Implikasi}

1. Implikasi Teoritis

Hasil penelitian menunjukkan dapat menambah pengetahuan dan wawasan baru tentang pengaruh multimedia interaktif terhadap karakter dan sikap.

2. Implikasi Praktis

Hasil penelitian ini secara praktis dapat digunakan sebagai bahan pertimbangan praktisi pendidikan dalam mengembangkan multimedia pembelajaran, agar peserta didik termotivasi mengikuti setiap proses pembelajaran dan meningkatkan karakternya. Dengan menggunakan multimedia interaktif, diharapkan peserta didik lebih bersemangat dan termotovasi dalam menyimak materi 'Karakterku', sehingga karakter mahasiswa dapat meningkat.

\section{Saran}

Berdasarkan hasil penelitian dan pembahasan, peneliti dapat memberikan saran sebagai berikut.

1. Bagi Pendidik

a. Pendidik sebaiknya dapat melakukan inovasi-inovasi dalam pembelajaran salah satunya dengan memanfaatkan multimedia interaktif dalam pembelajaran.

b. Media pembelajaran yang dibuat sebaiknya memperhatikan kebutuhan peserta didik, karakteristik materi pembelajaran.

2. Bagi Instansi Pendidikan

a. Instansi pendidikan sebaiknya dapat menyediakan fasilitas dalam menunjang kegiatan pembelajaran.

b. Fasilitas instansi pendidikan sebaiknya dapat dimanfaatkan semaksimal mungkin terutama untuk menunjang kegiatan pembelajaran.

3. Bagi Peneliti Selanjutnya

a. Penelitian ini dapat digunakan sebagai dasar untuk penelitian pengembangan multimedia interaktif selanjutnya.

b. Multimedia interaktif yang akan dikembangkan oleh peneliti selanjutnya dapat dikembangkan lagi untuk materi dan nilai-nilai karakter yang lain.

\section{DAFTAR PUSTAKA}

Abboed S. Abdullah. (1988). Kamus Istilah Agama Islam. Jakarta: Ikhwan.

Agung Trana Jaya.(2011). Hubungan Amanah dan Motivasi dengan Etos Kerja Kader Hidayatullah.Tesis, magister, tidak diterbitkan,Universitas Indonesia, Jakarta.

Mubarok, Achmad. (2009). Akhlak Mulia: Sebagai Konsep Pembangunan Karakter. GMPAM - YPC - WAP. 
Pius A. Partanto \& M. Dahlan Al Barry, (1994).Kamus Ilmiah Populer. Surabaya: Arkola.

Shodiq (2014). Pengukuran Keimanan: Perspektif Psikologi. Nadwa-Jurnal Pendidikan Islam. Vol. 8, Nomor 1, April 2014.

Syeikh Abdul Qadir al Jailani. (2002). Rahasia Sufi.Terj.Abdul Majid \& Khatib, Ar-RisalatulasSufiyyah. Yogyakarta: Pustaka Sufi.

Zakiah Daradjat, (1990). Ilmu Jiwa Agama. Jakarta: Bulan Bintang. 